\title{
Neurogenic orthostatic hypotension: pathophysiology, evaluation, and management
}

\author{
Manuela Metzler • Susanne Duerr • \\ Roberta Granata · Florian Krismer • \\ David Robertson · Gregor K. Wenning
}

Received: 13 September 2012/Revised: 24 October 2012/Accepted: 25 October 2012/Published online: 20 November 2012

(C) The Author(s) 2012. This article is published with open access at Springerlink.com

\begin{abstract}
Neurogenic orthostatic hypotension is a distinctive and treatable sign of cardiovascular autonomic dysfunction. It is caused by failure of noradrenergic neurotransmission that is associated with a range of primary or secondary autonomic disorders, including pure autonomic failure, Parkinson's disease with autonomic failure, multiple system atrophy as well as diabetic and nondiabetic autonomic neuropathies. Neurogenic orthostatic hypotension is commonly accompanied by autonomic dysregulation involving other organ systems such as the bowel and the bladder. In the present review, we provide an overview of the clinical presentation, pathophysiology, epidemiology, evaluation and management of neurogenic orthostatic hypotension focusing on neurodegenerative disorders.
\end{abstract}

Keywords Orthostatic hypotension .

Neurogenic orthostatic hypotension - Parkinson's disease · Multiple system atrophy · Pure autonomic failure ·

Autonomic dysfunction

\section{Introduction}

According to consensus guidelines, orthostatic hypotension $(\mathrm{OH})$ is defined as a sustained fall of systolic blood pressure by at least $20 \mathrm{mmHg}$ or diastolic blood pressure by

M. Metzler · S. Duerr · R. Granata · F. Krismer ·

G. K. Wenning $(\bowtie)$

Autonomic Function Laboratory, Division of Neurobiology, Department of Neurology, Innsbruck Medical University,

Anichstrasse 35, Innsbruck, Austria

e-mail: gregor.wenning@i-med.ac.at

D. Robertson

Autonomic Dysfunction Center, AA3228 MCN, Vanderbilt

University, Nashville, TN 37232-2195, USA
$10 \mathrm{mmHg}$ within $3 \mathrm{~min}$ of standing or head-up tilt [16]. Since the magnitude of blood pressure drop also depends on baseline values, it was suggested that a drop of $30 \mathrm{mmHg}$ may be a more appropriate criterion for $\mathrm{OH}$ in patients with supine hypertension [16]. Blood pressure is a clinical measure and the patients are not necessarily aware of its dysregulation The prevalence of $\mathrm{OH}$ increases with age and is commonly associated with neurodegenerative diseases including Parkinson's disease (PD), dementia with Lewy bodies (DLB), multiple system atrophy (MSA) and pure autonomic failure (PAF). In the general aged population, the prevalence rates of $\mathrm{OH}$ range between 5 and $30 \%[38,47,62,76]$ (reviewed in [40]). A more extensive overview on the rate of occurrence is given in Table 1.

Hallmark symptoms upon postural challenge include dizziness, visual disturbances, presyncope and syncope $[25,52]$. However, the majority of patients experience more subtle general complaints, such as tiredness, impaired cognitive performance [57], weakness, fatigue, leg buckling, visual blurring and orthostatic dyspnea [43]. Patients may also experience discomfort in the head, neck, shoulders or the chest. The latter may be reminiscent of anginal pain in the absence of coronary heart disease [60]. Symptoms are usually aggravated during hot weather or fever, after heavy meals, during prolonged standing and early in the morning [44]. In many patients, the worsening of symptoms early in the morning is caused by nocturnal diuresis due to the increase in supine blood pressure as shown in a study involving MSA patients [55].

\section{Pathophysiology}

Consciousness is critically dependent on continuous cerebral blood flow, and is lost within $6 \mathrm{~s}$ of shutdown of 
Table 1 Estimated prevalence of $\mathrm{OH}$ in different autonomic disorders

\begin{tabular}{lll}
\hline Condition & Prevalence rate $(\%)$ & References \\
\hline Aging & $10-30$ & {$[40]$} \\
Diabetes type I & 8.4 & {$[41]$} \\
Diabetes type II & 7.4 & {$[41]$} \\
Parkinson's disease & $37-58$ & {$[5,66,80]$} \\
Dementia with Lewy bodies & $30-50$ & {$[4,74,75]$} \\
MSA & 75 & {$[34]$} \\
PAF & 100 & {$[2]$} \\
\hline
\end{tabular}

Modified according to [40] (with kind permission from Springer Science + Business Media B.V.)

cerebral blood flow in human subjects [73]. Thus any stimulus or condition that perturbs cerebral perfusion may cause symptoms. Gravitationally mediated pooling of venous blood in the lower half of the body (i.e. legs and abdomen) begins almost immediately upon postural challenge and most of the venous pooling takes place within the first $10 \mathrm{~s}[10,72]$. The amount of blood transferred to lower body parts depends on the type of orthostatic stress and is estimated to $500-1,000 \mathrm{ml}[65,71,72]$. In addition, it was shown that plasma volume decreases during orthostatic stress [54]. As a consequence, the venous return to the heart is reduced which leads to a reduction in stroke volume by affecting end-diastolic filling of the right atrium ("Frank-Starling" relationship, [37]) resulting in a $20 \%$ decrease in cardiac output [77]. The compensatory reflex response is mainly mediated by the baroreceptors (arterial mechanoreceptors) which cause increased sympathetic outflow and suppressed vagal nerve activity resulting in increased peripheral resistance and improved venous return ultimately yielding to increased cardiac output [72]. However, in $\mathrm{OH}$ patients, an impaired increase in peripheral resistance could be observed that is most likely caused by disturbed neural reflex vasoconstriction [82].

It is noteworthy that two distinct kinds of pathological processes can dramatically alter autonomic blood pressure regulation in human subjects: baroreflex failure (BF) and neurogenic orthostatic hypotension $(\mathrm{NOH})$. In $\mathrm{BF}$, there is loss of afferent baroreflex engagement of central mechanisms of blood pressure control. However, central stimuli (such as anxiety, pain, anger, or excitement) can still engage an otherwise functional peripheral sympathetic system. These BF patients have extreme surges of blood pressure largely dependent on emotional state. Some of these surges (elevations above $250 \mathrm{mmHg}$ have been observed) are among the highest blood pressures encountered in contemporary clinical medicine $[27,33,59]$. Blood pressure may, however, be normal or occasionally low in the BF subjects when they are tired, during rest, or when they are sedated. Posture plays a relatively small role in the blood pressure level in many of these patients, although it has been reported in rare cases of $\mathrm{BF}$ with medullary lesions [12]. BF is generally caused by bilateral structural lesions in the carotid sinuses, the glossopharyngeal nerves or brainstem due to tumor, injury, or other damage to afferent pathways.

In contrast to the afferent or central lesion of BF, there is failure of noradrenaline release from sympathetic vasomotor neurons in $\mathrm{NOH}$ [16]. Loss of homeostatic mechanisms to control blood pressure fluctuations may contribute to the supine hypertension (systolic pressure $>180 \mathrm{mmHg}$ and/or diastolic pressure $>110 \mathrm{mmHg}$ ) commonly encountered in the spectrum of $\mathrm{NOH}$ [20]. This has to be considered when treating $\mathrm{NOH}$ in order to avoid the risk of chronic high blood pressure on the one hand and the risk of falling with its secondary consequences on the other hand.

\section{Predisposing factors}

Orthostatic hypotension is influenced by a range of factors; cross-sectional analysis not only suggests an influence of age, but also drug effects and orthostatic stress in neurological disorders, particularly PD, DLB and MSA as well as autonomic neuropathies [5, 40, 49, 66, 80]. The association between $\mathrm{OH}$ and advanced age may be explained by a number of predisposing factors that occur along with aging, including changes in baroreflex function, inadequate vasoconstrictor responses, reduced cardiac and vascular compliance, reduced blood volume and impaired efficiency of the skeletal muscle pump [16]. In addition, dehydration, deconditioning and poor nutrition contribute to the development of $\mathrm{OH}$ in the elderly population [58].

Another factor massively influencing $\mathrm{OH}$ prevalence is the effect of medication. Elderly subjects commonly require medications altering blood pressure, such as diuretics or antihypertensives, which are well known to either cause or exacerbate $\mathrm{OH}$. In addition, alpha-adrenoceptor antagonists in the treatment of benign prostatic hyperplasia, tricyclic antidepressants, vasodilatators, sympatholytics, and antiparkinsonian agents can increase risk of $\mathrm{OH}$ by impairing sympathetic tone or reducing peripheral vascular resistance [45]. Further, increased orthostatic stress in patients with parkinsonian conditions may be observed early in the morning, with a rise in core temperature, in activities which increase intrathoracic pressure (e.g. defecation, coughing) [64], prolonged standing, exertion, alcohol or carbohydrate ingestion [61]. A structured list of $\mathrm{OH}$ causes is presented in Table 2.

\section{NOH in neurodegenerative disease}

Neurogenic orthostatic hypotension can arise from primary neurodegenerative disorders or can be secondary to 
Table 2 Causes of orthostatic hypotension

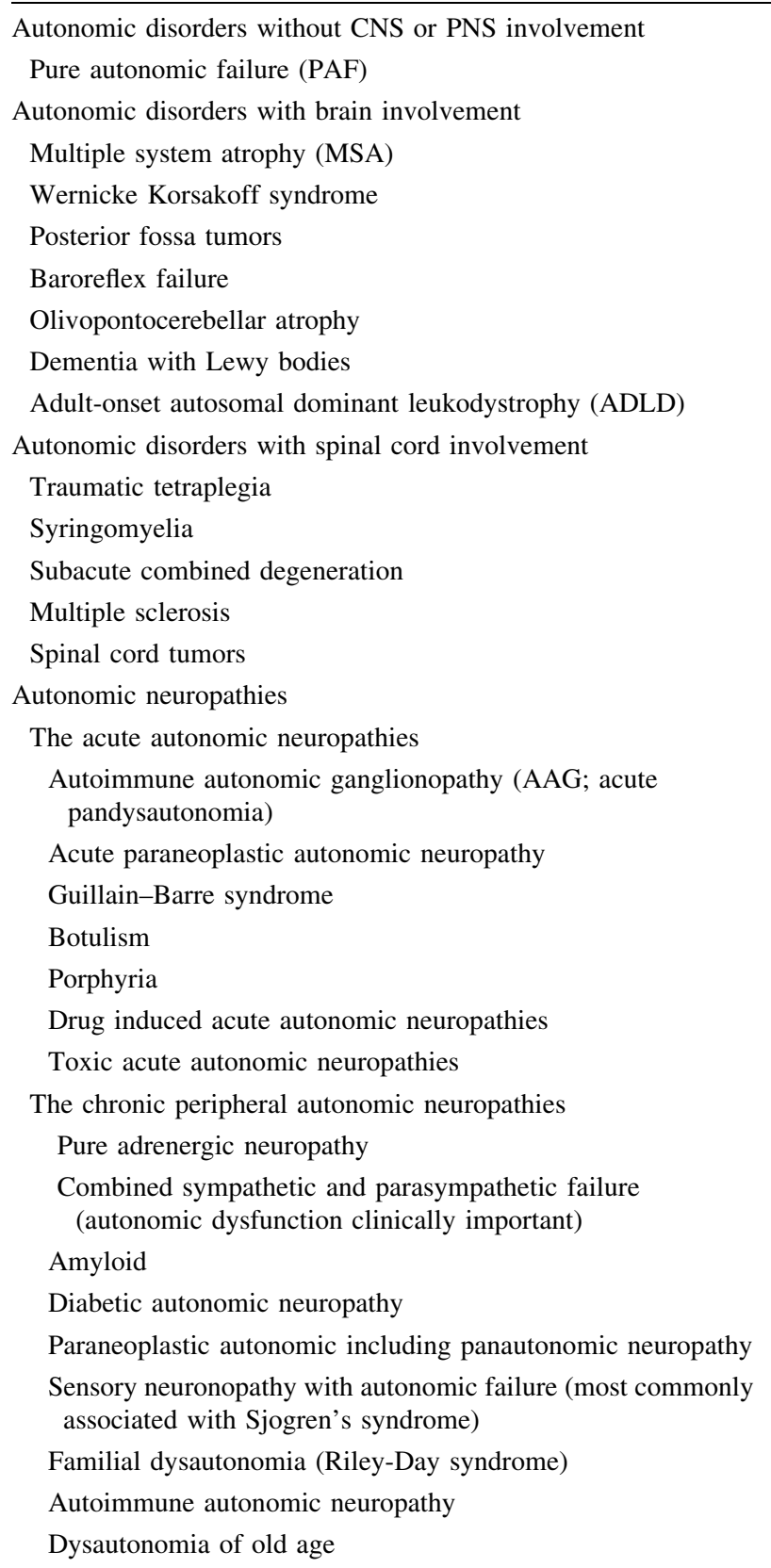

Modified according to [40], Table 3 (with kind permission from Springer Science + Business Media B.V.)

systemic conditions that influence peripheral nerve function [22]. PD, DLB, MSA and PAF belong to a category of neurodegenerative disorders known as $\alpha$-synucleinopathies due to their cellular hallmark feature that is $\alpha$-synuclein inclusion pathology [46]. The prevalence of $\mathrm{NOH}$ in PD ranges from 16 to $58 \%$ [66, 80]. Likewise, in DLB symptomatic $\mathrm{OH}$ is found in $30-50 \%$ of the patients separating DLB from other dementias including Alzheimer's disease and frontotemporal dementia [4, 74, 75].
Both PD and DLB show markedly decreased myocardial [123I]-metaiodobenzylguanidine uptake indicating severe impairment of the cardiac sympathetic innervations [7, 24]. MSA-associated $\mathrm{NOH}$ symptoms are present in more than two-thirds of all patients [34] and were, therefore, included into consensus diagnostic criteria [18]. PAF is a disease which is characterized by severe $\mathrm{NOH}$ associated with insidious onset, slow progression, modest gastrointestinal impairment, marked supine hypertension and often very low plasma noradrenalin levels representing a characteristic prototype of $\mathrm{NOH}[30]$.

\section{Evaluation}

Patients with $\mathrm{NOH}$ may split into two groups according to the site of the lesion with (1) disturbed central autonomic pathways and intact peripheral noradrenergic innervation or (2) loss of peripheral noradrenergic fibers [22]. Disruption of central autonomic pathways is commonly associated with normal or only slightly reduced plasma norepinephrine concentrations whereas the second group is characterized by low norepinephrine levels $[19,21]$.

The first step in the work-up of patients presenting with symptoms suggestive of NOH is the exclusion of potentially harmful causes such as acute bleeding and dehydration. Next, non-neurogenic causes (reviewed in [14]) including drugs, reduced cardiac output, endocrine disorders and excessive vasodilatation should be considered. In the absence of apparent causes, further work-up by cardiac autonomic function testing (CAFT) is indicated. Blood pressure and heart rate should be recorded in supine position and after 3 min of standing [16, 35]. In addition, Holter monitoring and 24-h blood pressure profiles accompanied by an accurate diary may be useful to determine the effects of daily life stimuli [48]. Moreover, the parasympathetic nervous system could be distinguished from the sympathetic adrenergic system by functional assessments. Heart rate variability upon deep respiration and during a Valsalva maneuver target the parasympathetic nervous system whereas blood pressure responses upon head-up tilt and during Valsalva maneuver point towards the sympathetic system $[1,11,50]$. Actions known to raise the blood pressure including isometric exercise, the cold pressor test (immersing the hand in ice slush for $90 \mathrm{~s}$ ) and mental arithmetic may be used to examine activation of different afferent or central pathways [48, 50]. Moreover, a careful work-up is required to diagnose neurological disorders underlying NOH. Present diagnostic criteria for PD are listed in Table 3 and consensus criteria for the diagnosis of MSA are presented in Fig. 1. Finally, the diagnosis of diabetic neuropathy requires utilization of clinical and physiological measures [3]. 
Table 3 Queen Square Brain Bank clinical diagnostic criteria for the diagnosis of Parkinson's disease

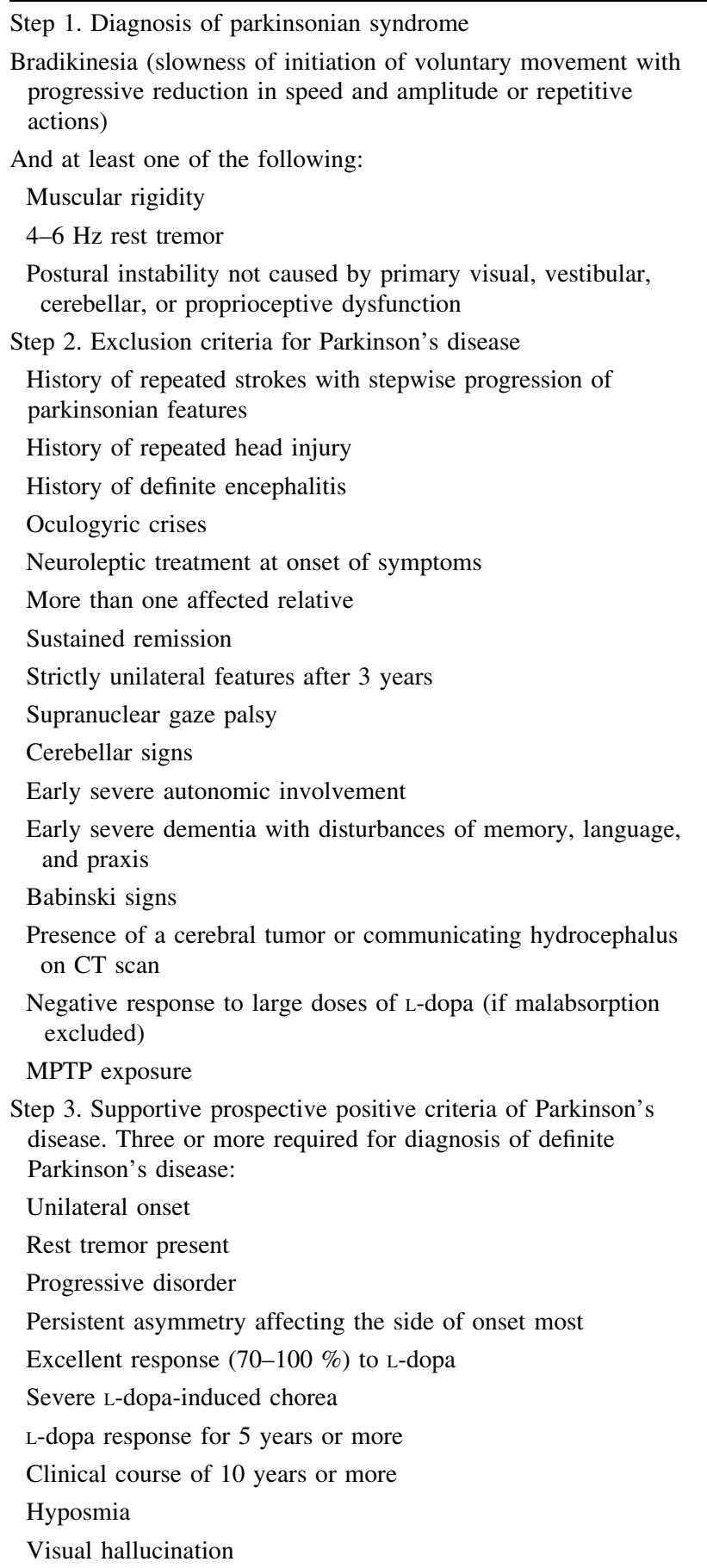

Reprinted from [36] Copyright (2009), with permission from Elsevier

Case presentations

\section{Case I}

A 77-year-old female was admitted to the hospital after a transient loss of consciousness. At the hospital, she indicated that she did not perceive the present "attack" and quickly felt comfortable again. Moreover, she was not aware of any dizziness, visual disturbances or light-headedness prior to her fainting spell. A history of recurring syncope that began in childhood was noted previously. Of note, the patient reported several cardiac risk factors including hyperlipidaemia, arterial hypertension and type 2 diabetes. Third-party descriptions did not suggest epileptic-like convulsions. During inpatient stay, another fainting fit was observed and measurements indicated low blood pressure. Subsequently, Holter monitoring and 24-h blood pressure profiles remained within normal range. Arterial hypertension was classified as non-dipper with nocturnal blood pressure drop of $3.8 \%$ systolic and $4.9 \%$ diastolic.

Tilt-table testing elicited a marked $\mathrm{NOH}$ with a supine blood pressure of $112 / 61 \mathrm{mmHg}$ dropping to $68 / 46 \mathrm{mmHg}$ after $3 \mathrm{~min}$ of head-up tilt, despite a constant heart rate of $62 \mathrm{bpm}$. A tilt-induced syncope occurred after $3.5 \mathrm{~min}$. Video monitoring observed orofacial automatisms and dystonic-myoclonic movements of the upper limbs as manifestations of cerebral hypoperfusion.

In the present case, medical history and clinical examinations suggest severe $\mathrm{NOH}$ in the context of cardiovascular autonomic diabetic neuropathy.

\section{Case II}

A 67-year-old male reported a 2-year history of progressive gait unsteadiness which initially started with slight balance difficulties. More recently, slurred speech, recurring falls without serious injuries and impaired fine motor skills appeared. In addition, the patient described symptoms suggestive of presyncope. In the clinical examination a cerebellar syndrome accompanied by mild akinetic-rigid parkinsonism was observed. Cerebral magnetic resonance imaging detected pontine and cerebellar atrophy. Presyncopal symptoms were further investigated by a simple standing test which confirmed the suspected diagnosis of $\mathrm{OH}$. Within $3 \mathrm{~min}$ of head-up tilt in tilt-table testing, a blood pressure drop of $76 \mathrm{mmHg}$ systolic and $51 \mathrm{mmHg}$ diastolic associated with an inadequate increase of $8 \mathrm{bpm}$ in heart rate appeared and further underscored the diagnosis of NOH. Overall, the patient met the Gilman criteria of probable MSA and received 9- $\alpha$-fluorohydrocortison which alleviated $\mathrm{OH}$ symptoms substantially as well as levodopa-benserazide which mediated a modest benefit towards parkinsonian symptoms only.

\section{Management}

A structured approach is important in the management of patients with $\mathrm{NOH}$. Wherever possible, underlying causes 


\section{Diagnostic Criteria - Multiple System Atrophy}

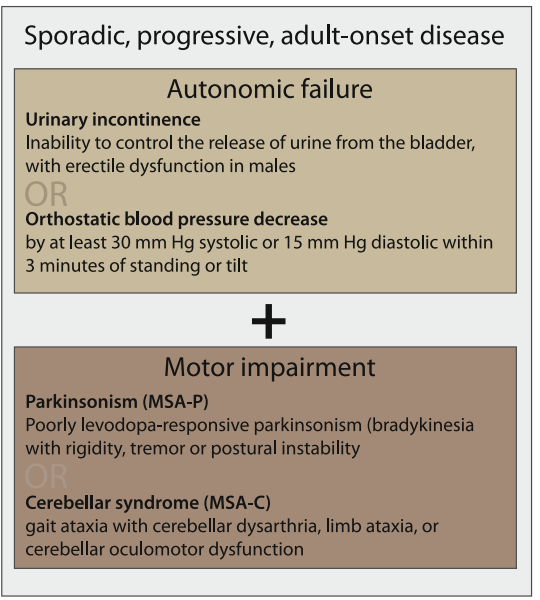

A

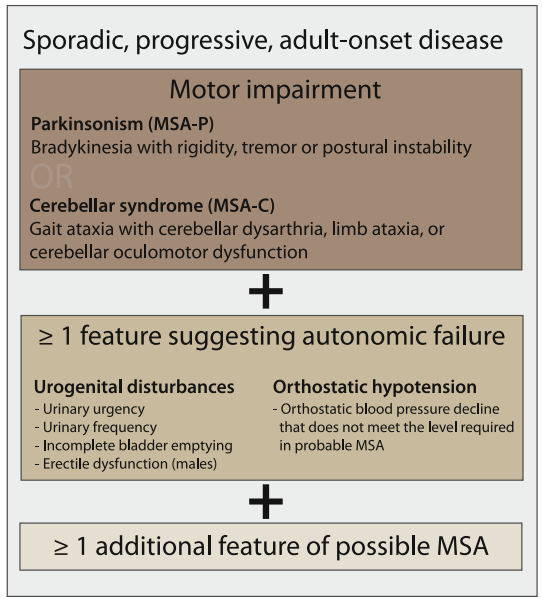

B

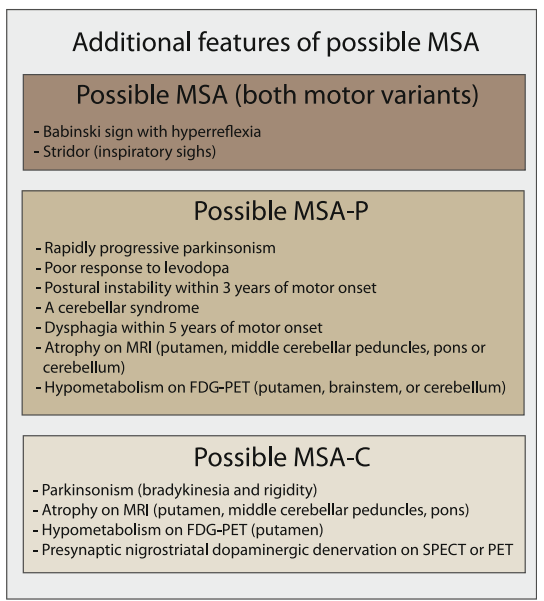

C

Fig. 1 Consensus criteria for the diagnosis of MSA. Modified according to [18]. a Diagnostic criteria for the diagnosis of probable MSA. b Diagnostic criteria for the diagnosis of possible MSA. c Additional features suggestive of MSA required for a diagnosis of possible MSA

should be identified by thorough work-up and the treatment strategy adapted accordingly. In addition, the magnitude of symptoms and the presence of asymptomatic $\mathrm{OH}$ should be considered. Available treatment options range from nonpharmacological options to aggressive drug therapy. While therapy of non-neurogenic $\mathrm{OH}$ is mostly straight-forward, $\mathrm{NOH}$ is often difficult to treat and a combination of nonpharmacological measures and drugs is required. Pharmacological agents can lead to different responses in patients with central neurodegeneration compared to those with peripheral neurodegeneration, and the latter has to be considered in the treatment as well.

Nevertheless, NOH massively affect patients' quality of life because of the disabling symptoms of autonomic failure. However, most of these symptoms could be alleviated by non-pharmacological and pharmacological measures. Therapeutic interventions should be implemented stepwise depending on the severity of symptoms. If non-pharmacological measures do not attenuate $\mathrm{NOH}$ symptoms sufficiently, pharmacological interventions may become necessary. Nevertheless, supine hypertension has to be taken into consideration in pharmacological treatment [15].

\section{Non-pharmacological interventions}

Non-pharmacological measures should be considered first in $\mathrm{NOH}$. Such measures include a stepwise raising from supine to standing position, physical exercise in order to avoid deconditioning, taking care of proper defection and compression stockings [14]. An abdominal bandage may also be useful in attenuating orthostatic dysregulation by restricting splanchnic blood pooling [9] and, similarly, physical maneuvers such as night time head-up tilt, leg-crossing, thigh contraction and squatting improve cerebral perfusion [79]. The spreading of total daily carbohydrate intake to multiple smaller meals was shown to beneficially affect orthostatic symptoms [39]. The effect of $500 \mathrm{ml}$ oral water ingestion typically increases blood pressure $20-30 \mathrm{mmHg}$ for about an hour, and sometimes greatly potentiates the pressor effect of other drugs [28]. Finally, adequate salt and fluid intake may be useful with dietary sodium intake of at least $10 \mathrm{~g}$ per day and a fluid intake of more than 21 per day [14, 29, 68, 78]. However, it has to be considered that increased fluid and salt intake may be harmful in patients with concomitant renal dysfunction and, thus, dietary fluid and salt intake requires regular check-up.

\section{Pharmacological treatment}

Two different mechanistic targets are approached in the pharmacological treatment of $\mathrm{NOH}$, namely volume expansion and vasoconstriction. In patients failing to respond appropriately to high salt diet and increased fluid intake, the prescription of $9-\alpha$-fluorohydrocortison, a synthetic mineralocorticoid, is indicated in order to increase plasma volume by renal sodium retention. Intriguingly, both of the latter effects return to normal over time, suggesting that increased peripheral vascular resistance (PVR) contributes to the observed pressor effect [8]. At the same time, PVR is the limiting factor of $9-\alpha$-fluorohydrocortison treatment resulting in dose-dependent supine hypertension [8]. Other adverse events include ankle edema, hypokalemia, headache and congestive heart failure.

On rare occasions, the vasopressin-analogue desmopressin could be applied to reduce nocturnal diuresis and 
expand plasma volume [51, 63]; however, those patients with impaired release of vasopressin due to neurodegeneration in hypothalamic areas such as MSA patients benefit the most [31]. Nevertheless, side effects including intoxication and hyponatremia have to be considered [51].

Bearing in mind that impaired norepinephrine release from sympathetic neurons is the central mechanism in $\mathrm{NOH}$ pathophysiology, sympathomimetic drugs yielding to vasoconstriction may be helpful in the treatment of $\mathrm{NOH}$, particularly in patients where plasma volume increase was insufficient to abolish orthostatic symptoms. However, so far, the only drug which has been approved by regulatory authorities (i.e. FDA, EMEA) for the treatment of NOH is the peripheral and directly acting $\alpha_{1}$-adrenoreceptor agonist midodrine. In two multi-centre double-blind placebocontrolled studies midodrine mediated beneficial effects that ameliorated orthostatic symptoms and increased standing blood pressure [42, 81]. More recently, the norepinephrine precursor L-dihydroxyphenylserine (L-DOPS, droxidopa) was shown to be effective in $\mathrm{NOH}$-associated neurodegenerative conditions [32, 53], and this agent seems near FDA approval for NOH in the United States. In rare causes of NOH like dopamine-beta hydroxylase deficiency, where noradrenaline is absent because of lack of the functional enzyme which produces noradrenaline, droxidopa can occasionally elicit a "Lazarus effect". Individuals with lifelong severe orthostatic hypotension and inability to stand for more than 2 min without losing consciousness may improve with droxidopa treatment to such an extent that may enable patients to successfully complete a marathon run [17]. Other sympathomimetics, particularly those with mixed or indirect effects, were either inferior to midodrine [13] or were not studied systematically [35]. However, these drugs may still be helpful in individual cases in which the patient did not respond to common pharmacologic options. A beneficial effect has been reported for other drugs in patients who have had limited or no response to the previously mentioned therapies. Of note, someone has to be well aware of the fact that all of the following drugs have to be administered off-label. Treatment of normocytic, normochromic anaemia in patients using erythropoietin increased standing blood pressure and improved orthostatic intolerance $[6,26,56]$. The cholinesterase inhibitor pyridostigmine improved ganglionic transmission and vascular adrenergic tone in primarily upright position, mediating a slight increase in diastolic blood pressure during standing without worsening supine hypertension [70]. Another drug being tested was yohimbine, which is known to release noradrenaline from sympathetic nerves via increasing neuronal output and antagonizing $\alpha_{2}$-adrenoceptors [23]. Intriguingly, patients with intact noradrenergic innervation experienced substantial increases in blood pressure and plasma noradrenaline levels, whereas attenuated effects were observed in patients with noradrenergic denervation $[67,69]$.

\section{Conclusion}

Neurogenic orthostatic hypotension can seriously impair patients' quality of life and is associated with increased morbidity, especially in the elderly. In several neurological diseases associated with autonomic failure, $\mathrm{NOH}$ is a major contributor to disease burden and reduced quality of life. A structured approach is important in the management of patients with NOH. Non-pharmacological interventions should be the first line of therapy. If the symptoms persist and the patients are severely affected, pharmacological interventions are required.

Acknowledgments This study was supported by a grant of the Austrian Science Fund (FWF): F04404-B19.

Conflicts of interest All authors declared that there are no conflicts of interest related to the present manuscript.

Ethical standards Due to the nature of the present manuscript (review), an ethical standards statement claiming that the study has been conducted in strict accordance with Declaration of Helsinki and its later amendments seems to be inappropriate to us since no orginial research is present in the paper.

Open Access This article is distributed under the terms of the Creative Commons Attribution License which permits any use, distribution, and reproduction in any medium, provided the original author(s) and the source are credited.

\section{References}

1. (1996) Assessment: clinical autonomic testing report of the Therapeutics and Technology Assessment Subcommittee of the American Academy of Neurology. Neurology 46:873-880

2. (1996) Consensus statement on the definition of orthostatic hypotension, pure autonomic failure, and multiple system atrophy. The Consensus Committee of the American Autonomic Society and the American Academy of Neurology. Neurology 46:1470

3. (1988) Consensus statement: Report and recommendations of the San Antonio conference on diabetic neuropathy. American Diabetes Association American Academy of Neurology. Diabetes care 11:592-597

4. Allan LM, Ballard CG, Allen J, Murray A, Davidson AW, McKeith IG, Kenny RA (2007) Autonomic dysfunction in dementia. J Neurol Neurosurg Psychiatry 78:671-677

5. Allcock LM, Ullyart K, Kenny RA, Burn DJ (2004) Frequency of orthostatic hypotension in a community based cohort of patients with Parkinson's disease. J Neurol Neurosurg Psychiatry 75:1470-1471

6. Biaggioni I, Robertson D, Krantz S, Jones M, Haile V (1994) The anemia of primary autonomic failure and its reversal with recombinant erythropoietin. Ann Intern Med 121:181-186 
7. Braune S, Reinhardt M, Schnitzer R, Riedel A, Lucking CH (1999) Cardiac uptake of [123I]MIBG separates Parkinson's disease from multiple system atrophy. Neurology 53:1020-1025

8. Chobanian AV, Volicer L, Tifft CP, Gavras H, Liang CS, Faxon D (1979) Mineralocorticoid-induced hypertension in patients with orthostatic hypotension. N Engl J Med 301:68-73

9. Diedrich A, Biaggioni I (2004) Segmental orthostatic fluid shifts. Clin Auton Res 14:146-147

10. Ebert TJ, Smith JJ, Barney JA, Merrill DC, Smith GK (1986) The use of thoracic impedance for determining thoracic blood volume changes in man. Aviat Space Environ Med 57:49-53

11. Ewing DJ, Martyn CN, Young RJ, Clarke BF (1985) The value of cardiovascular autonomic function tests: 10 years experience in diabetes. Diabetes Care 8:491-498

12. Fessel J, Robertson D (2006) Orthostatic hypertension: when pressor reflexes overcompensate. Nat Clin Pract Nephrol 2:424-431

13. Fouad-Tarazi FM, Okabe M, Goren H (1995) Alpha sympathomimetic treatment of autonomic insufficiency with orthostatic hypotension. Am J Med 99:604-610

14. Freeman R (2008) Current pharmacologic treatment for orthostatic hypotension. Clin Auton Res 18(Suppl 1):14-18

15. Freeman R (2003) Treatment of orthostatic hypotension. Semin Neurol 23:435-442

16. Freeman R, Wieling W, Axelrod FB, Benditt DG, Benarroch E, Biaggioni I, Cheshire WP, Chelimsky T, Cortelli P, Gibbons CH, Goldstein DS, Hainsworth R, Hilz MJ, Jacob G, Kaufmann H, Jordan J, Lipsitz LA, Levine BD, Low PA, Mathias C, Raj SR, Robertson D, Sandroni P, Schatz I, Schondorff R, Stewart JM, van Dijk JG (2011) Consensus statement on the definition of orthostatic hypotension, neurally mediated syncope and the postural tachycardia syndrome. Clin Auton Res 21:69-72

17. Garland EM, Raj SR, Demartinis N, Robertson D (2005) Case report: Marathon runner with severe autonomic failure. Lancet 366(Suppl 1):S13

18. Gilman S, Wenning GK, Low PA, Brooks DJ, Mathias CJ, Trojanowski JQ, Wood NW, Colosimo C, Durr A, Fowler CJ, Kaufmann H, Klockgether T, Lees A, Poewe W, Quinn N, Revesz T, Robertson D, Sandroni P, Seppi K, Vidailhet M (2008) Second consensus statement on the diagnosis of multiple system atrophy. Neurology 71:670-676

19. Goldstein DS, Holmes C, Sharabi Y, Brentzel S, Eisenhofer G (2003) Plasma levels of catechols and metanephrines in neurogenic orthostatic hypotension. Neurology 60:1327-1332

20. Goldstein DS, Pechnik S, Holmes C, Eldadah B, Sharabi Y (2003) Association between supine hypertension and orthostatic hypotension in autonomic failure. Hypertension 42:136-142

21. Goldstein DS, Polinsky RJ, Garty M, Robertson D, Brown RT, Biaggioni I, Stull R, Kopin IJ (1989) Patterns of plasma levels of catechols in neurogenic orthostatic hypotension. Ann Neurol 26:558-563

22. Goldstein DS, Sharabi Y (2009) Neurogenic orthostatic hypotension: a pathophysiological approach. Circulation 119:139-146

23. Grossman E, Rea RF, Hoffman A, Goldstein DS (1991) Yohimbine increases sympathetic nerve activity and norepinephrine spillover in normal volunteers. Am J Physiol 260:R142R147

24. Hanyu H, Shimizu S, Hirao K, Kanetaka H, Iwamoto T, Chikamori T, Usui Y, Yamashina A, Koizumi K, Abe K (2006) Comparative value of brain perfusion SPECT and [(123)I]MIBG myocardial scintigraphy in distinguishing between dementia with Lewy bodies and Alzheimer's disease. Eur J Nucl Med Mol imaging 33:248-253

25. Heims HC, Critchley HD, Martin NH, Jager HR, Mathias CJ, Cipolotti L (2006) Cognitive functioning in orthostatic hypotension due to pure autonomic failure. Clin Auton Res 16:113-120
26. Hoeldtke RD, Streeten DH (1993) Treatment of orthostatic hypotension with erythropoietin. N Engl J Med 329:611-615

27. Jordan J, Shannon JR, Black BK, Costa F, Ertl AC, Furlan R, Biaggioni I, Robertson D (1997) Malignant vagotonia due to selective baroreflex failure. Hypertension 30:1072-1077

28. Jordan J, Shannon JR, Diedrich A, Black B, Robertson D, Biaggioni I (2004) Water potentiates the pressor effect of ephedra alkaloids. Circulation 109:1823-1825

29. Jordan J, Shannon JR, Grogan E, Biaggioni I, Robertson D (1999) A potent pressor response elicited by drinking water. Lancet 353:723

30. Kaufmann H, Hague K, Perl D (2001) Accumulation of alphasynuclein in autonomic nerves in pure autonomic failure. Neurology 56:980-981

31. Kaufmann H, Oribe E, Miller M, Knott P, Wiltshire-Clement M, Yahr MD (1992) Hypotension-induced vasopressin release distinguishes between pure autonomic failure and multiple system atrophy with autonomic failure. Neurology 42:590-593

32. Kaufmann H, Saadia D, Voustianiouk A, Goldstein DS, Holmes C, Yahr MD, Nardin R, Freeman R (2003) Norepinephrine precursor therapy in neurogenic orthostatic hypotension. Circulation 108:724-728

33. Ketch T, Biaggioni I, Robertson R, Robertson D (2002) Four faces of baroreflex failure: hypertensive crisis, volatile hypertension, orthostatic tachycardia, and malignant vagotonia. Circulation 105:2518-2523

34. Kollensperger M, Geser F, Ndayisaba JP, Boesch S, Seppi K, Ostergaard K, Dupont E, Cardozo A, Tolosa E, Abele M, Klockgether T, Yekhlef F, Tison F, Daniels C, Deuschl G, Coelho M, Sampaio C, Bozi M, Quinn N, Schrag A, Mathias CJ, Fowler C, Nilsson CF, Widner H, Schimke N, Oertel W, Del Sorbo F, Albanese A, Pellecchia MT, Barone P, Djaldetti R, Colosimo C, Meco G, Gonzalez-Mandly A, Berciano J, Gurevich T, Giladi N, Galitzky M, Rascol O, Kamm C, Gasser T, Siebert U, Poewe W, Wenning GK (2010) Presentation, diagnosis, and management of multiple system atrophy in Europe: final analysis of the European multiple system atrophy registry. Mov Disord 25:2604-2612

35. Lahrmann H, Cortelli P, Hilz M, Mathias CJ, Struhal W, Tassinari M (2006) EFNS guidelines on the diagnosis and management of orthostatic hypotension. Eur J Neurol 13:930-936

36. Lees AJ, Hardy J, Revesz T (2009) Parkinson's disease. Lancet 373:2055-2066

37. Lewis RP, Sandler H (1971) Relationship between changes in left ventricular dimensions and the ejection fraction in man. Circulation 44:548-557

38. Lipsitz LA (1989) Orthostatic hypotension in the elderly. N Engl J Med 321:952-957

39. Lipsitz LA, Ryan SM, Parker JA, Freeman R, Wei JY, Goldberger AL (1993) Hemodynamic and autonomic nervous system responses to mixed meal ingestion in healthy young and old subjects and dysautonomic patients with postprandial hypotension. Circulation 87:391-400

40. Low PA (2008) Prevalence of orthostatic hypotension. Clin Auton Res 18(Suppl 1):8-13

41. Low PA, Denq JC, Opfer-Gehrking TL, Dyck PJ, O’Brien PC, Slezak JM (1997) Effect of age and gender on sudomotor and cardiovagal function and blood pressure response to tilt in normal subjects. Muscle Nerve 20:1561-1568

42. Low PA, Gilden JL, Freeman R, Sheng KN, McElligott MA (1997) Efficacy of midodrine vs placebo in neurogenic orthostatic hypotension. A randomized, double-blind multicenter study. Midodrine Study Group. JAMA 277:1046-1051

43. Low PA, Opfer-Gehrking TL, McPhee BR, Fealey RD, Benarroch EE, Willner CL, Suarez GA, Proper CJ, Felten JA, Huck CA et al (1995) Prospective evaluation of clinical characteristics of orthostatic hypotension. Mayo Clin Proc 70:617-622 
44. Low PA, Singer W (2008) Management of neurogenic orthostatic hypotension: an update. Lancet Neurol 7:451-458

45. Luther JM (2012) Drug-induced autonomic dysfunction. In: Robertson D, Biaggioni I, Burnstock G, Low PA, Paton JFR (eds) Primer on the autonomic nervous system. Elsevier, San Diego, pp 511-514

46. Marti MJ, Tolosa E, Campdelacreu J (2003) Clinical overview of the synucleinopathies. Mov Disord 18(Suppl 6):S21-S27

47. Masaki KH, Schatz IJ, Burchfiel CM, Sharp DS, Chiu D, Foley D, Curb JD (1998) Orthostatic hypotension predicts mortality in elderly men: the Honolulu Heart Program. Circulation 98:2290-2295

48. Mathias CJ (2003) Autonomic diseases: clinical features and laboratory evaluation. J Neurol Neurosurg Psychiatry 74(Suppl 3):iii31-iii41

49. Mathias CJ (1995) Orthostatic hypotension: causes, mechanisms, and influencing factors. Neurology 45:S6-S11

50. Mathias CJ, Bannister R (1999) Investigations of autonomic disorders. In: Mathias CJ, Bannister R (eds) Autonomic failure: a textbook of clinical disorders of the autonomic nervous system. Oxford University Press, New York

51. Mathias CJ, Fosbraey P, da Costa DF, Thornley A, Bannister R (1986) The effect of desmopressin on nocturnal polyuria, overnight weight loss, and morning postural hypotension in patients with autonomic failure. Br Med J (Clin Res Ed) 293:353-354

52. Mathias CJ, Mallipeddi R, Bleasdale-Barr K (1999) Symptoms associated with orthostatic hypotension in pure autonomic failure and multiple system atrophy. J Neurol 246:893-898

53. Mathias CJ, Senard JM, Braune S, Watson L, Aragishi A, Keeling JE, Taylor MD (2001) L-threo-dihydroxyphenylserine (L-threoDOPS; droxidopa) in the management of neurogenic orthostatic hypotension: a multi-national, multi-center, dose-ranging study in multiple system atrophy and pure autonomic failure. Clin Auton Res 11:235-242

54. Matzen S, Perko G, Groth S, Friedman DB, Secher NH (1991) Blood volume distribution during head-up tilt induced central hypovolaemia in man. Clin Physiol 11:411-422

55. Ozawa T, Tanaka H, Nakano R, Sato M, Inuzuka T, Soma Y, Yoshimura N, Fukuhara N, Tsuji S (1999) Nocturnal decrease in vasopressin secretion into plasma in patients with multiple system atrophy. J Neurol Neurosurg Psychiatry 67:542-545

56. Perera R, Isola L, Kaufmann H (1995) Effect of recombinant erythropoietin on anemia and orthostatic hypotension in primary autonomic failure. Clin Auton Res 5:211-213

57. Poda R, Guaraldi P, Solieri L, Calandra-Buonaura G, Marano G, Gallassi R, Cortelli P (2012) Standing worsens cognitive functions in patients with neurogenic orthostatic hypotension. Neurol Sci 33:469-473

58. Robertson D (2008) The pathophysiology and diagnosis of orthostatic hypotension. Clin Auton Res 18(Suppl 1):2-7

59. Robertson D, Hollister AS, Biaggioni I, Netterville JL, Mosqueda-Garcia R, Robertson RM (1993) The diagnosis and treatment of baroreflex failure. N Engl J Med 329:1449-1455

60. Robertson D, Kincaid DW, Haile V, Robertson RM (1994) The head and neck discomfort of autonomic failure: an unrecognized aetiology of headache. Clin Auton Res 4:99-103

61. Robertson D, Wade D, Robertson RM (1981) Postprandial alterations in cardiovascular hemodynamics in autonomic dysfunction states. Am J Cardiol 48:1048-1052

62. Rutan GH, Hermanson B, Bild DE, Kittner SJ, LaBaw F, Tell GS (1992) Orthostatic hypotension in older adults. The Cardiovascular Health Study. CHS Collaborative Research Group. Hypertension 19:508-519

63. Sakakibara R, Matsuda S, Uchiyama T, Yoshiyama M, Yamanishi T, Hattori T (2003) The effect of intranasal desmopressin on nocturnal waking in urination in multiple system atrophy patients with nocturnal polyuria. Clin Auton Res 13:106-108
64. Schmidt C, Herting B, Prieur S, Junghanns S, Schweitzer K, Globas C, Schols L, Reichmann H, Berg D, Ziemssen T (2009) Valsalva manoeuvre in patients with different Parkinsonian disorders. J Neural Transm 116:875-880

65. Self DA, White CD, Shaffstall RM, Mtinangi BL, Croft JS, Hainsworth R (1996) Differences between syncope resulting from rapid onset acceleration and orthostatic stress. Aviat Space Environ Med 67:547-554

66. Senard JM, Rai S, Lapeyre-Mestre M, Brefel C, Rascol O, Rascol A, Montastruc JL (1997) Prevalence of orthostatic hypotension in Parkinson's disease. J Neurol Neurosurg Psychiatry 63:584-589

67. Senard JM, Rascol O, Durrieu G, Tran MA, Berlan M, Rascol A, Montastruc JL (1993) Effects of yohimbine on plasma catecholamine levels in orthostatic hypotension related to Parkinson disease or multiple system atrophy. Clin Neuropharmacol 16:70-76

68. Shannon JR, Diedrich A, Biaggioni I, Tank J, Robertson RM, Robertson D, Jordan J (2002) Water drinking as a treatment for orthostatic syndromes. Am J Med 112:355-360

69. Sharabi Y, Eldadah B, Li ST, Dendi R, Pechnik S, Holmes C, Goldstein DS (2006) Neuropharmacologic distinction of neurogenic orthostatic hypotension syndromes. Clin Neuropharmacol 29:97-105

70. Singer W, Sandroni P, Opfer-Gehrking TL, Suarez GA, Klein CM, Hines S, O'Brien PC, Slezak J, Low PA (2006) Pyridostigmine treatment trial in neurogenic orthostatic hypotension. Arch Neurol 63:513-518

71. Sjostrand T (1952) The regulation of the blood distribution in man. Acta Physiol Scand 26:312-327

72. Smit AA, Halliwill JR, Low PA, Wieling W (1999) Pathophysiological basis of orthostatic hypotension in autonomic failure. J Physiol 519(Pt 1):1-10

73. Smith BA, Clayton EW, Robertson D (2011) Experimental arrest of cerebral blood flow in human subjects: the red wing studies revisited. Perspect Biol Med 54:121-131

74. Sonnesyn H, Nilsen DW, Rongve A, Nore S, Ballard C, Tysnes OB, Aarsland D (2009) High prevalence of orthostatic hypotension in mild dementia. Dement Geriatr Cogn Disord 28:307313

75. Thaisetthawatkul $\mathrm{P}$, Boeve BF, Benarroch EE, Sandroni P, Ferman TJ, Petersen R, Low PA (2004) Autonomic dysfunction in dementia with Lewy bodies. Neurology 62:1804-1809

76. Tilvis RS, Hakala SM, Valvanne J, Erkinjuntti T (1996) Postural hypotension and dizziness in a general aged population: a fouryear follow-up of the Helsinki Aging Study. J Am Geriatr Soc 44:809-814

77. Wang Y, Marshall RJ, Shepherd JT (1960) The effect of changes in posture and of graded exercise on stroke volume in man. J Clin Invest 39:1051-1061

78. Wieling W, Van Lieshout JJ, Hainsworth R (2002) Extracellular fluid volume expansion in patients with posturally related syncope. Clin Auton Res 12:242-249

79. Wieling W, van Lieshout JJ, van Leeuwen AM (1993) Physical manoeuvres that reduce postural hypotension in autonomic failure. Clin Auton Res 3:57-65

80. Wood BH, Bilclough JA, Bowron A, Walker RW (2002) Incidence and prediction of falls in Parkinson's disease: a prospective multidisciplinary study. J Neurol Neurosurg Psychiatry 72:721-725

81. Wright RA, Kaufmann HC, Perera R, Opfer-Gehrking TL, McElligott MA, Sheng KN, Low PA (1998) A double-blind, dose-response study of midodrine in neurogenic orthostatic hypotension. Neurology 51:120-124

82. Ziegler MG, Lake CR, Kopin IJ (1977) The sympathetic-nervoussystem defect in primary orthostatic hypotension. N Engl J Med 296:293-297 